\section{Jubiläum! Dr. Kaschny PR gibt es seit 20 Jahren}

Gutes bewahren und konsequent weiterentwickeln: Die Agentur für Öffentlichkeitsarbeit Dr. Kaschny PR GmbH (KPR) besteht seit 1996 und geht jetzt mit erfahrener Mannschaft die nächsten 20 Jahre an. Das Unternehmen aus Bad Homburg blickt zum Jubiläum auf eine Erfolgsgeschichte auf dem Gebiet der nationalen und internationalen Gesundheits-PR zurück - und ganz im Sinne des kürzlich verstorbenen Firmengründers voller Tatendrang in die Zukunft.

Die Agentur hat sich im Lauf der vergangenen 20 Jahre als Adresse speziell in der dentalen Öffentlichkeitsarbeit etabliert. Zu einem zentralen Merkmal der Agentur zählt dabei seit jeher die Zusammenfüh- rung von Mitarbeitern mit sowohl wissenschaftlichem als auch journalistischem Know-how unter 1 Dach. Stets flieBen beide Aspekte in die Arbeiten aus dem Hause KPR ein. Unverändert wird auch in Zukunft der eigene Anspruch an die Qualität und den Mehrwert der Arbeit sein. „Im Sinne des kürzlich verstorbenen Dr. Peter Kaschny wird die Agentur mit ihrer erfahrenen Mannschaft auch in den nächsten Jahren ihre Kompetenzen und Leistungen konsequent ausbauen, um insbesondere den Bereich der Zahnheilkunde weiter zu fördern“, so Geschäftsführer Thomas Hammann anlässlich des Jubiläums. „Gleichzeitig möchte ich mich im Namen der gesamten Agentur bei unseren Kunden und langjährigen Partnern auf Medienseite für das Vertrauen bedanken.“

Nach einer Pressemitteilung der Dr. Kaschny PR GmbH, Bad Homburg

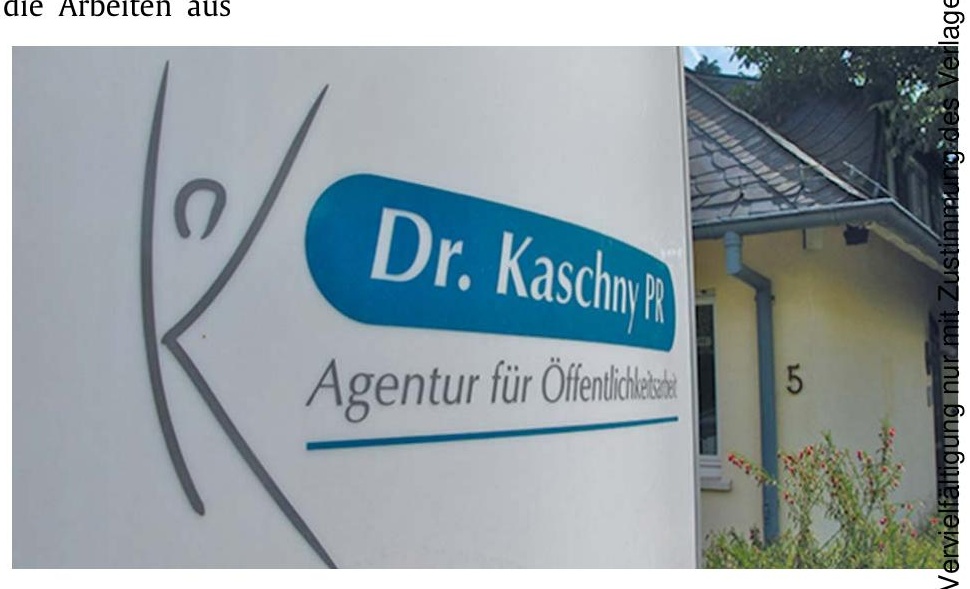

